\title{
Ornis Svecica fledges into the modern publishing landscape
}

\author{
Ornis Svecica flyger ut \\ i den moderna publikationsvärlden
}

\author{
Martin Stervander ${ }^{1}$ [D \& Sören Svensson ${ }^{2}$ \\ ${ }^{1}$ Institute of Ecology and Evolution, University of Oregon, Eugene OR 97403, USA | martin@stervander.com \\ 2 Department of Biology, Lund University, Ecology Building, 22362 Lund, Sweden | soren.svensson@biol.lu.se
}

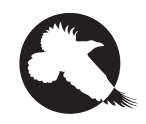

THIS YEAR, BirdLife Sweden-previously the Swedish Ornithological Society-entered its seventy-fifth year of operation. Through 1990, research reports were published in its journal Vår Fågelvärld. However, these reports were available in Swedish only. In 1991, Vår Fågelvärld changed character to a more general birding magazine. There was a niche to fill with a scientific ornithological journal, and thus Ornis Svecica was founded. The journal was deliberately aimed at both academic researchers and non-professional ornithologists (Svensson et al. 1991), and while initially catering mainly to contributions with a connection to the Swedish avifauna, this soon changed and Ornis Svecica welcomes contributions irrespective of the geographic origin of the birds as well as the authors.

After the publication of the last issue of Volume 28 during 2018, the publisher decided that Ornis Svecica will make the transition from a printed journal to an online only journal. Since then, the editorial board has worked to execute this, and appointed Martin Stervander as managing editor, focusing on implementing a publishing system and updating the journal's profile for a relaunch during spring 2019. We are now happy to publish the first contributions of Volume 29 as PDF files available at the journal's new website, which can be reached at os.birdlife.se. The site is built using the Open Journal Systems (OJS) platform from the Public Knowledge Project, and hosted at Lund University Libraries, at which librarian Martina Ramstedt has offered invaluable assistance. OJS is an open source solution that handles journal management, including manuscript submission and the review process, as well as the actual publishing. One of the many advantages is that we can now assign a Digital Object Identifier (DOI) to each published paper. The DOIs provide a stable address to papers, and can be used for dissemination and tracking. In addition to the PDF version, each article has a landing page with summary information and metadata, to which the DOI links.

Ornis Svecica relaunches with a few differences, apart from now only being published online. As there are no longer physical issues to collect material for, we have transitioned to a continuous publication model, in which a paper is published online as soon as it has been accepted after peer review and revisions. This is a win-win situation, as it benefits the authors as well as 
the readers, in that the final product rapidly becomes available. Moreover, there is no real reason to stick to issues, and we thus publish articles directly under the annual volumes, as before with continuous pagination through each volume.

Another difference is the look of the journal and the papers. We have developed a logotype that clearly nods back to the Common Raven Corvus corax photographed by Torbjörn Lilja, which embellished the covers of Ornis Svecica between 1991 and 1998. The layout and typography of the papers have also changed from all Times New Roman to a profile that we hope will facilitate the reading through more distinct styles of headers, body text, and captions. Tomas Dettlaff has generously helped us in this process.

Not only the look is new, but in connection with the relaunch, the composition of the editorial board changes a bit. Two members have served since the start, the editor-in-chief Sören Svensson and Åke Lindström. Dennis Hasselquist, who also has served as editor since the journal started, now leaves the board. A process has been initiated to aquire new editors. As a first step we are most pleased to welcome two new editors: Assistant Professor Anouschka R. Hof (Wageningen University), and Associate Professor Helena Westerdahl (Lund University).

In this relaunch volume, our first contributions are both authored by non-professional ornithologists who have published several previous articles in Ornis Svecica. Andersson (2019) describes the population development in the early range expansion phase for European Stonechats Saxicola rubicola in Southern Sweden, while Sondell et al. (2019) investigates foraging prerequisites in farmland for the vulnerable Ortolan Bunting Emberiza hortulana. For the cover, photographer Ivan Sjögren lent us his excellent photo of a singing Ortolan Bunting taken at Hyvlingeåsen in Uppland.

As a reader, we hope that you will enjoy Ornis Sveci$c a$ 's new site. You will find the papers published in this volume, but in due course all $>500$ papers published in the journal will be made available and easily searchable. At the time of the relaunch on the World Migratory Bird Day 11 May 2019, individual papers from volumes 27 onwards are available, while all other contributions are currently available in PDF files of the full issues. If you want to stay up-to-date, and be notified of new publications, please register your profile at the website os.birdlife.se.

As a presumptive author, note the following:

1. Ornis Svecica welcomes contributions whose main language is English or Swedish (also Danish, Norwegian), with a detailed summary in the other language. However, we offer editorial assistance with the summary to anyone not proficient in the alternative language.

2. Unlike most scientific journals, Ornis Svecica neither charges a penny for publishing contributions, nor charges the readers. It is thus entirely Open Access and entirely free.

3. Once a contribution has been accepted, the time to being available online in its final version is short.

4. All contributions are published under the Creative Commons BY 4.0 license, which means that the authors hold the copyright, but that it is free for anyone to reproduce and modify the contents, as long as the authors and the original source are credited.

We hope that you will want to share and spread Ornis Svecica's papers via social media, which is most easily done by referring to the DOI link. The journal is present as@OrnisSvecica on Twitter and Facebook, and we hope that you will follow us there, and tag us in any relevant posts.

We hope that you as a reader will enjoy the updated Ornis Svecica, and we hope that we will receive many contributions from academics and non-professional ornithologists alike! We accept research papers, short communications, review articles, and forum texts. For further information, and detailed author guidelines, please refer to the site os.birdlife.se.

\section{References}

Andersson R. 2019. Populationsutveckling hos svarthakad buskskvätta Saxicola rubicola under expansionens inledningsskede i Västsverige. [Population development of European Stonechat Saxicola rubicola during the initial phase of its expansion in Western Sweden]. Ornis Svecica 29: 26-36. https://doi.org/10.34080/os.v29.19555

Sondell J, Durà C \& Persson M. 2019. Breeding prerequisites for Ortolan Bunting Emberiza hortulana in Swedish farmland, with special focus on foraging. Ornis Svecica 29: 5-25. https://doi. org/10.34080/os.v29.19554

Svensson S, Bensch S, Grahn M, Hasselquist D, Hedenström A, Holmgren N, Källander H, Lindström ̊̊, Nilsson J-Å, Sandberg R, Smith HG \& Åkesson S. 1991. Välkommen till Ornis Svecica! Ornis Svecica 1: 1-2. https://doi.org/10.34080/os.v1.19614 


\section{Svensk version}

I år inträdde BirdLife Sverige, tidigare Sveriges Ornitologiska Förening, sitt sjuttiofemte verksamhetsår. Till och med 1990 publicerades forskningsrapporter på svenska i medlemstidningen Vår Fågelvärld. År 1991 förändrades Vår Fågelvärld och fick en mer allmän innehållsprofil. En nisch behövde fyllas med en vetenskaplig tidskrift och 1991 grundades Ornis Svecica. Tidskriften riktades medvetet till både akademiska forskare och icke-professionella ornitologer (Svensson m. fl. 1991) och från att till en början främst publicerat uppsatser om den svenska fagelfaunan tar tidskriften numera in artiklar oberoende av såväl fåglarnas som författarnas geografiska hemvist.

Efter publiceringen av sista häftet av volym 28, 2018, bestämdes att Ornis Svecica skulle övergå från tryckt tidskrift till att publiceras enbart på nätet. Sedan dess har redaktionen arbetat för att uppnå detta mål och utnämnt Martin Stervander till verkställande redaktör med uppgift att förnya tidskriftens profil för presentation i maj 2019. Vi är nu glada över att kunna publicera de första bidragen i volym 29 som PDF på tidskriftens nya plattform, som nås på os.birdlife.se. Den bygger på plattformen Open Journal Systems (OJS) från Public Knowledge Project under värdskap av Lunds universitetsbibliotek, där bibliotekarien Martina Ramstedt har bjudit på ovärderlig hjälp. OJS är en öppen lösning som tillgodoser tidskriftens olika behov, inklusive mottagandet av manuskript och granskningsprocessen, samt själva publiceringen. En av de många fördelarna är att vi nu kan ge varje uppsats en unik identifikation, en $\mathrm{Di}$ gital Object Identifier (DOI). En DOI ger en stabil adress till uppsatsen och kan användas för att både sprida och spåra den. Förutom PDF-versionen har varje uppsats en översiktssida med sammanfattande information och metadata, som DOI länkar till.

Ornis Svecica återuppstår i sin nya skepnad med få skillnader utöver att i fortsättningen bara finnas online. Eftersom det inte längre finns skäl att samla uppsatser i fysiska häften övergår vi till kontinuerlig publicering, vilket innebär att varje uppsats publiceras så snart den accepterats efter granskning och revision. På detta vinner både författare och läsare eftersom slutprodukten blir tillgänglig snabbt. Ingen uppdelning på flera häften per år är heller aktuell. Uppsatserna kommer därför inte att ha några häftesnummer utan bara löpande sidnumrering inom årsvolymen.

En annan skillnad mot tidigare är utseendet hos både tidskriften och uppsatserna. Vi har utvecklat en logotyp som tydligt syftar bakåt på den korp som fotograferades av Torbjörn Lilja och som prydde omslagen på Ornis Svecica åren 1991 till och med 1998. Grafisk formgivning och typografi har, med Tomas Dettlaffs generösa assistans, utvecklats för att underlätta läsandet genom att utnyttja tydligare stilar för rubriker, brödtext och text för figurer och tabeller, i stället för den tidigare genomgånde användningen av Times New Roman.

Inte bara utseendet är nytt. I samband med nylanseringen på nätet sker också ändringar i redaktionens sammansättning. Två redaktörer har varit med från start, huvudredaktören Sören Svensson och Åke Lindström. Det har också Dennis Hasselquist, som nu lämnar redaktionen. Vi har inlett en process för att förstärka redaktionen med nya redaktörer och är glada över att redan kunna välkomna två stycken: Anouschka R. Hof (biträdande professor vid Wageningen universitet) och Helena Westerdahl (docent och biträdande professor vid Lunds universitet).

I nylanseringens första volym är båda bidragen författade av ornitologer som inte är professionella fågelforskare, men de har tidigare publicerat flera artiklar i Ornis Svecica. Andersson (2019) beskriver den sentida expansionen av svarthakad buskskvätta Saxicola rubicola i södra Sverige och Sondell m. fl. (2019) undersöker förutsättningarna för den sårbara ortolansparven Emberiza hortulana på jordbruksmark. För omslaget har fotografen Ivan Sjögren lånat oss sitt utsökta foto av en sjungande ortolansparv från Hyvlingeåsen i Uppland.

Vi hoppas att du som läsare ska bli nöjd med vår nya webbplats. Där finner du uppsatserna för årets volym allteftersom de publiceras. Men i sinom tid kommer alla de över fem hundra uppsatserna som tidigare publicerats i Ornis Svecica att bli tillgängliga och sökbara. Vid nylanseringen på World Migratory Bird Day den 11 maj 2019 finns uppsatserna i volymerna 27-28 tillgängliga individuellt medan andra volymer tills vidare bara finns tillgängliga som hela häften. Om 
du vill få information om nya uppsatser i Ornis Svecica så snart de publiceras kan du med fördel registrera dig på vår webbplats os.birdlife.se.

Ska du skicka in en uppsats för granskning och möjlig publicering är det några saker som är bra att veta:

1. Ornis Svecica välkomnar uppsatser på engelska eller svenska (även danska, norska) med en utförlig sammanfattning på det andra språket. Redaktionen bistår med detta vid behov.

2. Till skillnad från de flesta vetenskapliga tidskrifter tar Ornis Svecia inte det minsta betalt, vare sig av läsare eller författare. Den är således fullständigt Open Access och helt gratis.

3. Tidsspannet mellan att ett bidrag har accepterats och publicering online är kort.

4. Alla bidrag publiceras enligt reglerna för Creative Commons BY 4.o, vilket innebär att författarna behål- ler upphovsrätten, men att det är fritt för envar att återskapa och förändra innehållet så länge författarna och ursprungskälla anges.

Vi hoppas att du vill dela och sprida uppsatserna i Ornis Svecica via sociala medier, vilket görs enklast genom länkning till DOI. Tidskriften finns som @OrnisSvecica på Twitter och Facebook, och vi hoppas att du vill följa oss där, samt taggar oss när du skriver ett inlägg.

Vi hoppas att du som läsare ska uppskatta den nya Ornis Svecica och att vi ska få in många uppsatser såväl från akademiker som från ornitologer som inte har fåglar som yrke! Vi publicerar forskningsuppsatser, korta rapporter och översiktsartiklar, men också mer allmänna inlägg under rubriken "Forum". För ytterligare information och detaljerade riktlinjer för författare hänvisar vi till os.birdlife.se.

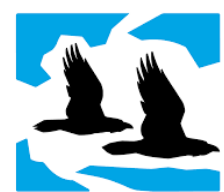

Birdlife Sverige

Ornis Svecica (ISSN 2003-2633) is an open access, peer-reviewed scientific journal published in English and Swedish by BirdLife Sweden. It covers all aspects of ornithology, and welcomes contributions from scientists as well as non-professional ornithologists. Accepted articles are published at no charge to the authors. Read papers or make a submission at os.birdlife.se.

Ornis Svecica (ISSN 2003-2633) är en fritt tillgänglig granskad vetenskaplig tidskrift som ges ut på svenska och engelska av BirdLife Sverige. Den täcker ornitologins alla områden och välkomnar bidrag från såväl forskare som icke-professionella ornitologer. Accepterade uppsatser publiceras utan kostnad för författarna. Läs uppsatser eller skicka in ditt bidrag på os.birdlife.se. 